\title{
Fungal Communities in Sediments Along a Depth Gradient in the Eastern Tropical Pacific
}

\author{
Keilor Rojas-Jimenez ${ }^{1 *}$, Hans-Peter Grossart ${ }^{2,3 *}$, Erik Cordes ${ }^{4}$ and Jorge Cortés ${ }^{1,5}$ \\ ${ }^{1}$ Escuela de Biología, Universidad de Costa Rica, San José, Costa Rica, ${ }^{2}$ Institute for Biochemistry and Biology, University \\ of Potsdam, Potsdam, Germany, ${ }^{3}$ Department of Experimental Limnology, Leibniz-Institute of Freshwater Ecology \\ and Inland Fisheries, Stechlin, Germany, ${ }^{4}$ Department of Biology, Temple University, Philadelphia, PA, United States, \\ ${ }^{5}$ Centro de Investigación en Ciencias del Mar y Limnología, Universidad de Costa Rica, San José, Costa Rica
}

\section{OPEN ACCESS}

Edited by:

Ramiro Logares,

Spanish National Research Council,

Spain

Reviewed by:

Marlis Reich,

University of Bremen, Germany

Virginia P. Edgcomb,

Woods Hole Oceanographic

Institution, United States

*Correspondence:

Keilor Rojas-Jimenez keilor.rojas@gmail.com

Hans-Peter Grossart

hgrossart@igb-berlin.de

Specialty section:

This article was submitted to

Aquatic Microbiology,

a section of the journal

Frontiers in Microbiology

Received: 22 June 2020

Accepted: 21 October 2020

Published: 06 November 2020

Citation:

Rojas-Jimenez K, Grossart H-P,

Cordes E and Cortés J (2020) Fungal

Communities in Sediments Along

a Depth Gradient in the Eastern

Tropical Pacific.

Front. Microbiol. 11:575207.

doi: 10.3389/fmicb.2020.575207
Deep waters represent the largest biome on Earth and the largest ecosystem of Costa Rica. Fungi play a fundamental role in global biogeochemical cycling in marine sediments, yet, they remain little explored. We studied fungal diversity and community composition in several marine sediments from 16 locations sampled along a bathymetric gradient (from a depth of 380 to $3,474 \mathrm{~m}$ ) in two transects of about 1,500 km length in the Eastern Tropical Pacific (ETP) of Costa Rica. Sequence analysis of the V7-V8 region of the 18S rRNA gene obtained from sediment cores revealed the presence of 787 fungal amplicon sequence variants (ASVs). On average, we detected a richness of 75 fungal ASVs per sample. Ascomycota represented the most abundant phylum with Saccharomycetes constituting the dominant class. Three ASVs accounted for ca. 63\% of all fungal sequences: the yeast Metschnikowia (49.4\%), Rhizophydium (6.9\%), and Cladosporium (6.7\%). We distinguished a cluster composed mainly by yeasts, and a second cluster by filamentous fungi, but we were unable to detect a strong effect of depth and the overlying water temperature, salinity, dissolved oxygen (DO), and $\mathrm{pH}$ on the composition of fungal communities. We highlight the need to understand further the ecological role of fungi in deep-sea ecosystems.

Keywords: deep-sea, aquatic fungi, biodiversity, Metschnikowia, Costa Rica

\section{INTRODUCTION}

Fungi inhabited the oceans, including the deep-sea ecosystem, long before they conquered terrestrial environments. In addition, considering that the deep sea represents the largest biome on Earth, there is a paucity of studies on the diversity and ecology of fungi in this ecosystem compared to the rest of the ocean. Furthermore, what is known about the microbial ecology in deepsea sediments is mainly about bacteria and archaea (Edgcomb et al., 2011; Nagano and Nagahama, 2012; Dekas et al., 2016; Xu et al., 2018). Therefore, detailed knowledge of deep-sea fungi is required to understand better the overall fungal contribution to marine food webs and biogeochemical cycles at the global scale (Manohar and Raghukumar, 2013; Barone et al., 2018; Drake and Ivarsson, 2018; Grossart et al., 2019; Román et al., 2019; Hassett et al., 2020).

Fungal communities have been studied in only a small part of the great variety of habitats that exist in deep waters. Some of these habitats include sediments of hydrothermal vents, methane-cold seeps, oxygen-minimum zones, and associated with other macro-organisms 
(Nagahama et al., 2011; Zhang et al., 2016; Batista-García et al., 2017). In addition, some studies have shown that the subseafloor represents a vast ecosystem where micro-aerobic respiration occurs and where microbial life subsist, even hundreds of meters below the seafloor (D'Hondt, 2002; Roy et al., 2012; D'Hondt et al., 2015; Ivarsson et al., 2016a; Nagano et al., 2016).

In recent years, there has been a growing interest in studying fungal communities in deep-sea environments using culturedependent and, to an increasing extent, culture-independent methods. Abundant fungal populations have been observed in a variety of deep-sea locations such as asphalt seeps in São Paulo Plateau (Nagano et al., 2017), methane seeps in the Kuroshima Knoll (Takishita et al., 2006), hydrothermal vents in the MidAtlantic Ridge (Le Calvez et al., 2009; Xu et al., 2017), sediments of the Peru Trench (Edgcomb et al., 2011), the East Indian Ocean (Zhang et al., 2014), the High Arctic (Zhang et al., 2015), the Mariana Trench (Xu et al., 2016, 2018), the Yellow Sea (Li et al., 2016), the Mediterranean Sea (Barone et al., 2018), the Yap Trench (Li et al., 2019), and subsurface sediments in Suruga-Bay (Nagano et al., 2016).

In general, Ascomycota and Basidiomycota are the most abundant groups in deep-sea ecosystems, representing between $70-80 \%$ and $10-20 \%$ of the sequences, respectively. Some of the most abundant filamentous fungal genera include Penicillium, Aspergillus, Cladosporium, and Fusarium, while some of the most abundant yeasts include Rhodotorula, Cryptococcus, Candida, Rhodosporidium, and Metschnikowia (Li et al., 2016, 2019; Xu et al., 2016, 2019; Zhang et al., 2016; Nagano et al., 2017; Barone et al., 2018; Wang et al., 2019).

In deep waters, fungi must be adapted to the total absence of light, low temperatures, and high hydrostatic pressure. Fungi in the deep-sea sediments may survive on marine snow, which consists of organic matter derived from photosynthesis that takes place in the photic layer (Bochdansky et al., 2017). In addition to performing aerobic respiration, fungi could be capable of carrying out processes such as fermentation, sulfate reduction, methanogenesis (D'Hondt, 2002; Lenhart et al., 2012), and possibly lithoautotrophy (López-García et al., 2003; Nealson et al., 2005; Ivarsson et al., 2016b). Transcriptomic analyses also confirm fungi as active members of deep-sea sediments, performing activities related to complex carbon and fatty acid metabolism (Pachiadaki et al., 2016). These metabolic processes may be more critical for fungi in deep waters since it has been observed that as depth increases, fungal populations exhibit a more multitrophic lifestyle (Li et al., 2019).

Considering the enormous area to be explored for fungal diversity and function in deep-sea sediments, the existing studies are minimal and often lack an adequate spatial and temporal resolution (Grossart and Rojas-Jimenez, 2016; Grossart et al., 2019; Morales et al., 2019). Therefore, there is still a large number of geographical locations that have not yet been studied, including the Eastern Tropical Pacific (ETP). The deep-sea waters of the ETP constitute a particularly important ecosystem in Costa Rica since they represent about $90 \%$ of the whole territory (Cortés, 2016, 2019).

The Costa Rican ETP comprises a chain of mountains and submarine volcanoes across the subduction zone of the
Cocos and Caribbean tectonic plates. Here, there is a high diversity of microhabitats (Lizano, 2001; Protti et al., 2012; Rojas and Alvarado, 2012) including methane seeps (Sahling et al., 2008; Levin et al., 2012, 2015). Previous studies have shown high endemism and diversity of macro- and microorganisms in this region (Rusch et al., 2007; Cortés, 2008, 2019; RojasJiménez, 2018). Also, the Costa Rican ETP is part of a marine corridor that extends through Isla del Coco to the Galapagos Islands in Ecuador, which represents an essential site for the conservation and regeneration of marine species throughout the ETP (Cortés, 2012).

In this work, we have explored the diversity and composition of fungal communities in deep-sea sediments of the Costa Rican ETP. Two expeditions were carried out with transects of approximately $1,500 \mathrm{~km}$ length each, and sediments were sampled at 16 locations at depths between $380 \mathrm{~m}$ and 3,474 m. We extracted DNA from subsamples of each sediment core, sequenced the $18 \mathrm{~S}$ rRNA gene, and performed a subsequent bioinformatic analysis. This work confirms the high abundance and diversity of fungi in sediments of the ETP region. We expect that our results will support current efforts to conserve this region by providing a baseline of the high diversity of fungal species and microhabitats found in its deep-sea waters.

\section{MATERIALS AND METHODS}

We analyzed the fungal community composition in sediments along a depth gradient in the ETP of Costa Rica, across two transects of ca. 1,500 km length each (Figure 1). All

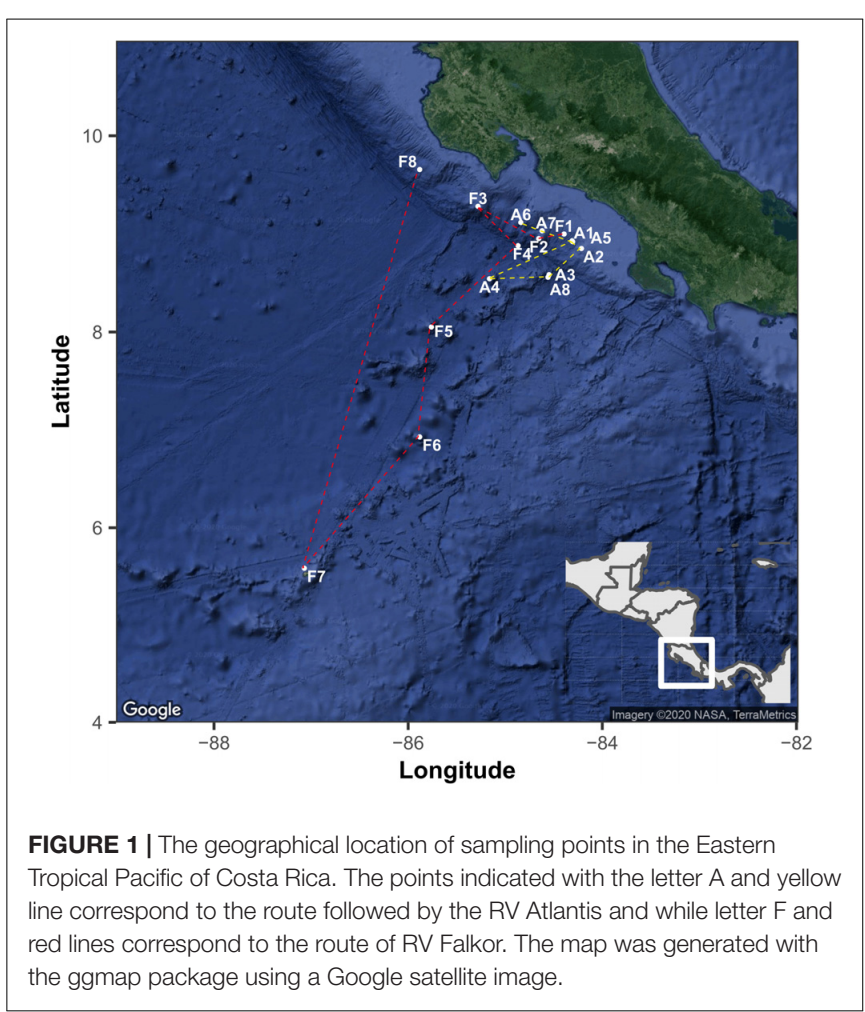


samples were collected with the permission of the Ministry of Environment and Energy of Costa Rica (SINAC-CUSBSE-PIR-032-2018; R-070-2018-OT-CONAGEBIO). The RV Atlantis surveyed the Pacific continental margin of Costa Rica from October 24th to November 5th, 2018, from the continental slope to the offshore seamounts across a subduction zone. In this region, several methane-rich seeps have been detected (Sahling et al., 2008; Levin et al., 2012, 2015). All sediment cores were collected by the human-occupied vehicle (HOV) Alvin equipped with mechanical, maneuverable arms. We analyzed eight sediment-cores from this expedition. The following year, the RV Falkor surveyed the seamounts extending from the mainland to the Isla del Coco National Park between January 6th and 21st, 2019. This region comprises several seamounts and natural gas seeps and provides an important corridor for highly specialized biological communities occupying the area. The sediment cores were collected employing the remotely operated vehicle (ROV) SuBastian, which is also equipped with mechanical, maneuverable arms. We analyzed another eight sediment cores from this expedition. The cores consist of an acrylic sleeve $(6.7 \mathrm{~cm}$ diameter by $25.4 \mathrm{~cm}$ long) with a PVC cap and a rubber flap on the top to allow for water to escape while inserting the core while sealing as the core is removed from the sediment. The cores were kept in a "quiver" which is a PVC sleeve with a stopper at the bottom. They are sealed to the outside and are not contaminated by seawater on the way to the surface. Because the cores traveled from a higher pressure to a lower pressure, we rule out seawater intrusion. The transit time of the ROV on the longest recovery ( $>3,200 \mathrm{~m}$ depth) was approximately $2 \mathrm{~h}$. Further details of the sampling sites, dates, depth, temperature, salinity, dissolved oxygen (DO), and $\mathrm{pH}$ are shown in Table 1.

We used the top $15 \mathrm{~cm}$ of the cores. Nearly one gram of the upper $(1-2 \mathrm{~cm})$, middle $(6-7 \mathrm{~cm})$, and lower
(13-14 cm) parts of each core was deposited into a $1.5 \mathrm{ml}$ tube, stored at $-20^{\circ} \mathrm{C}$ on board the vessel and at $-80^{\circ} \mathrm{C}$ in the laboratory. The sediment DNA was extracted with a DNA isolation kit (PowerSoil $^{\circledR}$, Qiagen, Carlsbad, CA, United States) following the manufacturer's instructions. From some subsamples, unfortunately, it was not possible to obtain enough DNA for subsequent analyzes, so in total, we retrieved 40 DNA samples (out of the 48 possible) from the 16 cores sampled in both transects. The V7 and V8 regions of the 18S rRNA gene were amplified with primers FF390/FR1 (Vainio and Hantula, 2000), using the HotStarTaq Plus Master Mix Kit (Qiagen, Carlsbad, CA, United States). The PCR conditions consisted of $95^{\circ} \mathrm{C}$ for $3 \mathrm{~min}$ initial denaturation followed by 35 cycles at $95^{\circ} \mathrm{C}$ for $45 \mathrm{~s}, 53^{\circ} \mathrm{C}$ for $1 \mathrm{~min}, 72^{\circ} \mathrm{C}$ for $1 \mathrm{~min}$, and a final extension at $72^{\circ} \mathrm{C}$ for $5 \mathrm{~min}$. Multiple samples are pooled together in equal proportions based on their molecular weight and DNA concentrations. Pooled samples were purified using calibrated Ampure XP beads. The pooled and purified PCR product of nearly $350 \mathrm{bp}$ were used to prepare illumina DNA library. Sequencing was performed at MR DNA ${ }^{1}$ (Shallowater, TX, United States) on a MiSeq sequencer with v3 $2 \times 250 \mathrm{nt}$ chemistry (Illumina, San Diego, CA, United States).

We used the DADA2 pipeline version 1.16 to process the Illumina-sequenced paired-end fastq files and to generate a table of ASVs, which are higher-resolution analogs of the traditional OTUs (Callahan et al., 2016). Briefly, we removed primers and adapters, inspected the quality profiles of the reads, filtered and trimmed sequences with a quality score $<30$, estimated error rates, modeled and corrected amplicon errors and inferred the sequence variants. Then, we merged the forward and reverse reads to obtain the full denoised sequences, removed chimeras, and constructed the ASV table. To assign taxonomy

${ }^{1}$ www.mrdnalab.com

TABLE 1 | Sites of the Eastern Tropical Pacific of Costa Rica sampled in this study, with the respective values of the environmental variables measured.

\begin{tabular}{|c|c|c|c|c|c|c|c|c|c|}
\hline Sample & RV & Site & Date & Depth (m) & Temperature $\left({ }^{\circ} \mathrm{C}\right)$ & Salinity (PSU) & DO (mg/L) & $\mathrm{pH}$ & Data sources* \\
\hline A1 & Atlantis & Mound $12^{\star \star}$ & $24 / 10 / 18$ & 996 & 5.06 & 34.57 & 1.10 & 7.62 & 1,6 \\
\hline $\mathrm{A} 2$ & Atlantis & Quepos slide ${ }^{\star \star}$ & 25/10/18 & 380 & 11.75 & 34.76 & 0.20 & 7.71 & 1,7 \\
\hline A3 & Atlantis & Quepos plateau & $26 / 10 / 18$ & 2,200 & 2.06 & 34.60 & 3.73 & 8.06 & $2,4,6$ \\
\hline A4 & Atlantis & Seamount 3 & 28/10/18 & 1,383 & 3.35 & 34.60 & 1.67 & 7.70 & $2,4,6$ \\
\hline A5 & Atlantis & Mound $11^{\star \star}$ & $3 / 11 / 18$ & 1,024 & 4.83 & 34.57 & 1.24 & 7.67 & 6,7 \\
\hline A6 & Atlantis & Jaco scar** & $4 / 11 / 18$ & 1,788 & 2.54 & 34.63 & 2.42 & 7.61 & 1,6 \\
\hline A7 & Atlantis & Parrita seep ${ }^{\star \star}$ & $5 / 11 / 18$ & 1,410 & 3.41 & 34.60 & 2.21 & 7.71 & 6 \\
\hline A8 & Atlantis & Quepos plateau & 26/10/18 & 1,873 & 3.50 & 34.61 & 3.11 & 8.06 & 1,3 \\
\hline $\mathrm{F} 1$ & Falkor & The thumb** & 10/1/19 & 1,072 & 4.54 & 34.58 & 1.22 & 7.69 & 4,7 \\
\hline $\mathrm{F} 2$ & Falkor & Parrita scar & $11 / 1 / 19$ & 1,419 & 3.35 & 34.61 & 2.08 & 7.67 & 4,5 \\
\hline F3 & Falkor & Rio bongo & 13/1/19 & 659 & 14.41 & 34.93 & 1.50 & 7.60 & 4,7 \\
\hline $\mathrm{F} 4$ & Falkor & Subduction seep & $14 / 1 / 19$ & 3,474 & 1.88 & 34.66 & 4.20 & 7.71 & 4,5 \\
\hline F5 & Falkor & Seamount 5.5 & $15 / 1 / 19$ & 1,540 & 3.00 & 34.62 & 2.64 & 7.70 & 4,5 \\
\hline F6 & Falkor & Seamount 7 & 16/1/19 & 1,320 & 4.11 & 34.59 & 1.80 & 7.67 & 4,5 \\
\hline F7 & Falkor & Coco Canyon & 18/1/19 & 950 & 5.02 & 34.57 & 1.40 & 8.12 & 4,5 \\
\hline F8 & Falkor & Mound Jaguar** & 25/1/19 & 1,903 & 2.43 & 34.63 & 3.13 & 7.75 & 4,5 \\
\hline
\end{tabular}

*1, AUV Sentry sensors; 2, HOV Alvin sensors; 3, HOV Alvin niskin bottle; 4, ROV SuBastian sensors; 5, ROV SuBastian niskin bottle; 6, RV Atlantis CTD; 7, RV Falkor CTD. ${ }^{* *}$ Seep areas. 
to the ASVs we used the function assignTaxonomy, which is an implementation of a naive Bayesian classifier method using as input the set of sequences to be classified and a training set of reference sequences with known taxonomy, which in this case was Silva SSURef NR $132^{2}$ (Quast et al., 2013). The assignments were verified and further curated using the BLAST tool of NCBI Genbank. All ASVs that appeared only once in the dataset were discarded. The sequence data were deposited into the NCBI Sequence Read Archive under BioProject PRJNA632873 and BioSample accessions: SAMN14924417-SAMN14924456³.

Statistical analyses and their visualization were performed with the $\mathrm{R}$ statistical program (R-Core-Team, 2019) and the RStudio interface. Package Vegan v2.5-6 (Oksanen et al., 2020) was used to calculate alpha diversity estimators and, non-metric multidimensional scaling analyses (NMDS). Data tables with the ASV abundances were normalized into relative abundances and then converted into a Bray-Curtis similarity matrix. To determine if there were significant differences between the fungal community composition according to factors such as depth or transect, we used the non-parametric multivariate analysis of variance (PERMANOVA) and pairwise PERMANOVA (adonis2 function with 999 permutations). For the network analysis, we selected the 10 most abundant fungal ASVs, which corresponded to $82 \%$ of the total number of fungal sequences. We considered a valid co-occurrence event if the Spearman's correlation coefficient was $>0.5$ (Junker, 2008). The resulting correlation matrix was converted into an undirected matrix. We used the $\mathrm{R}$ package igraph v1.2.4.2 to generate the network based on the Kamada-Kawai layout algorithm (Csardi and Nepusz, 2006).

The environmental data was collected from measurements performed in the water column overlying the sediment cores and for which various instruments and sensors were used (Table 1). Temperature and salinity data were obtained from the conductivity-temperature-depth (CTD) sensors on the HOV Alvin (CTD SeaBird SBE49) and ROV SuBastian (CTD Seabird FastCAT SBE49), which were also equipped with Niskin bottles for water sampling. There was a DO optode on the ROV SuBastian (Aanderaa $3841 \mathrm{O} 2$ Optode) as well as the autonomous underwater vehicle (AUV) Sentry which was deployed over some of the sites during the 2018 Atlantis expedition. Niskin rosettes with attached CTDs were also deployed from the Atlantis and Falkor over the sites, and the Falkor CTD had a DO optode as well. DO data were compiled from a combination of these sources. DO data for the samples from the 2018 Alvin dives were derived from either the Sentry data (if available from the site) or calculated from a curve fitted from the closest CTD cast, typically, from the same site. DO data for the 2019 SuBastian push core samples was determined from SuBastian optode. The $\mathrm{pH}$ data were exclusively from the water samples obtained by the rosette deployed from the ship or the niskin bottles on the submersibles. Water samples were brought to room temperature and the pHT (total scale) was measured using an Orion 5 Star $\mathrm{pH}$ meter and glass electrode (ROSS Ultra pH/ATC Triode 8107BNUMD,

\footnotetext{
${ }^{2}$ https://www.arb-silva.de/documentation/release-132/

${ }^{3}$ https://www.ncbi.nlm.nih.gov/bioproject/PRJNA632873
}

Hamilton, NJ, United States) in triplicate within $4 \mathrm{~h}$ of collection (Dickson et al., 2007).

\section{RESULTS AND DISCUSSION}

We determined the presence of 787 fungal ASV in marine sediments of the Eastern Tropical Pacific of Costa Rica, obtained from 16 locations (40 subsamples) along a bathymetric gradient from 380 to $3,474 \mathrm{~m}$. Fungi represented $59.72 \%$ of the 2,746,436 sequences obtained from the specific primers used for the amplification of the V7-V8 region of the $18 \mathrm{~S}$ rRNA gene. Ascomycota was the most abundant phylum, which represented $43 \%$ of all fungal sequences and $71 \%$ of the ASVs. The second most abundant fungal group was Basidiomycota, representing nearly $3 \%$ of the sequences but $22 \%$ of the ASVs. Most of the ASVs within Basidiomycota were assigned to the order Agaricales. Chytridiomycota represented the third most abundant fungal group, with $3.5 \%$ of the sequences and 2.79\% of the ASVs. Other less frequent fungal groups observed in this ecosystem were, Blastocladiomycota, LKM11, LKM15, Mucoromycota, and Zoopagomycota (Figure 2).

When analyzing the relative abundances at the class level, we detected a total of 32 classes in the deep-sea sediments, where Saccharomycetes was the most prominent in the majority of the samples. In samples where Saccharomycetes was dominant, they were typically accompanied by the presence of Chytridiomycetes. There was a second group of samples with high abundances of Eurotiomycetes, Dothideomycetes, and Agaricomycetes, but

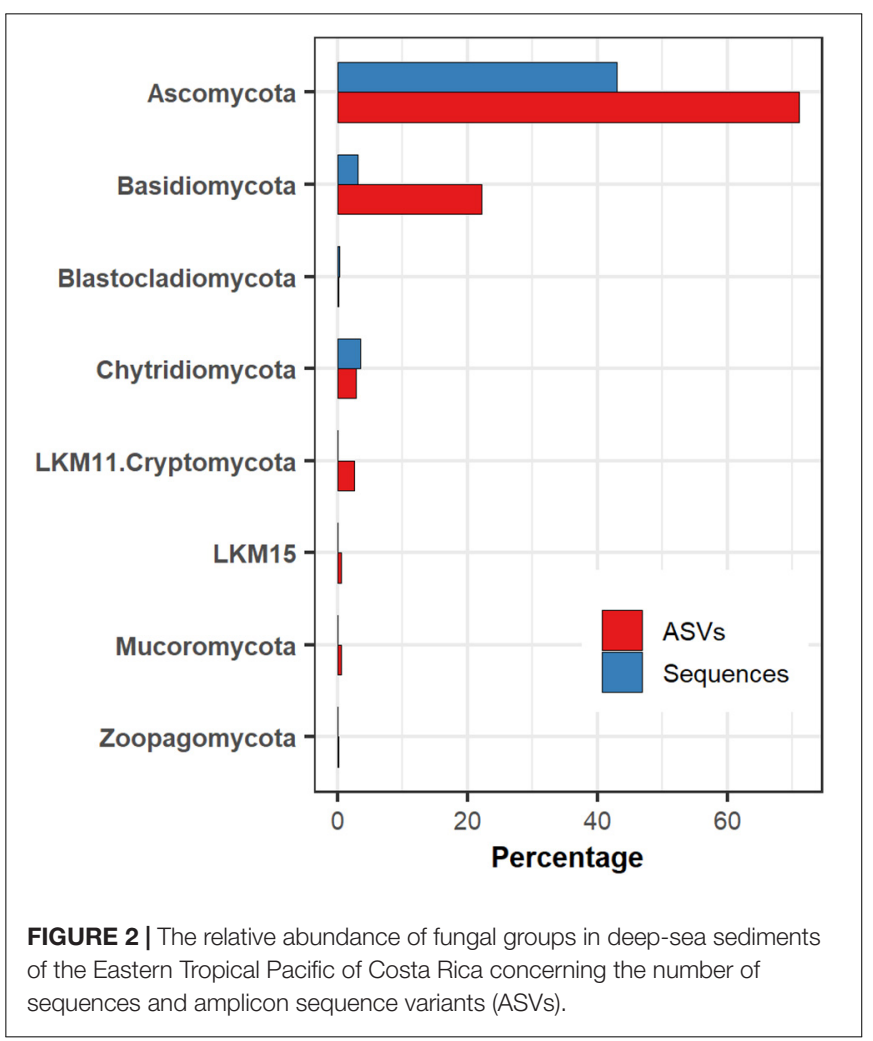



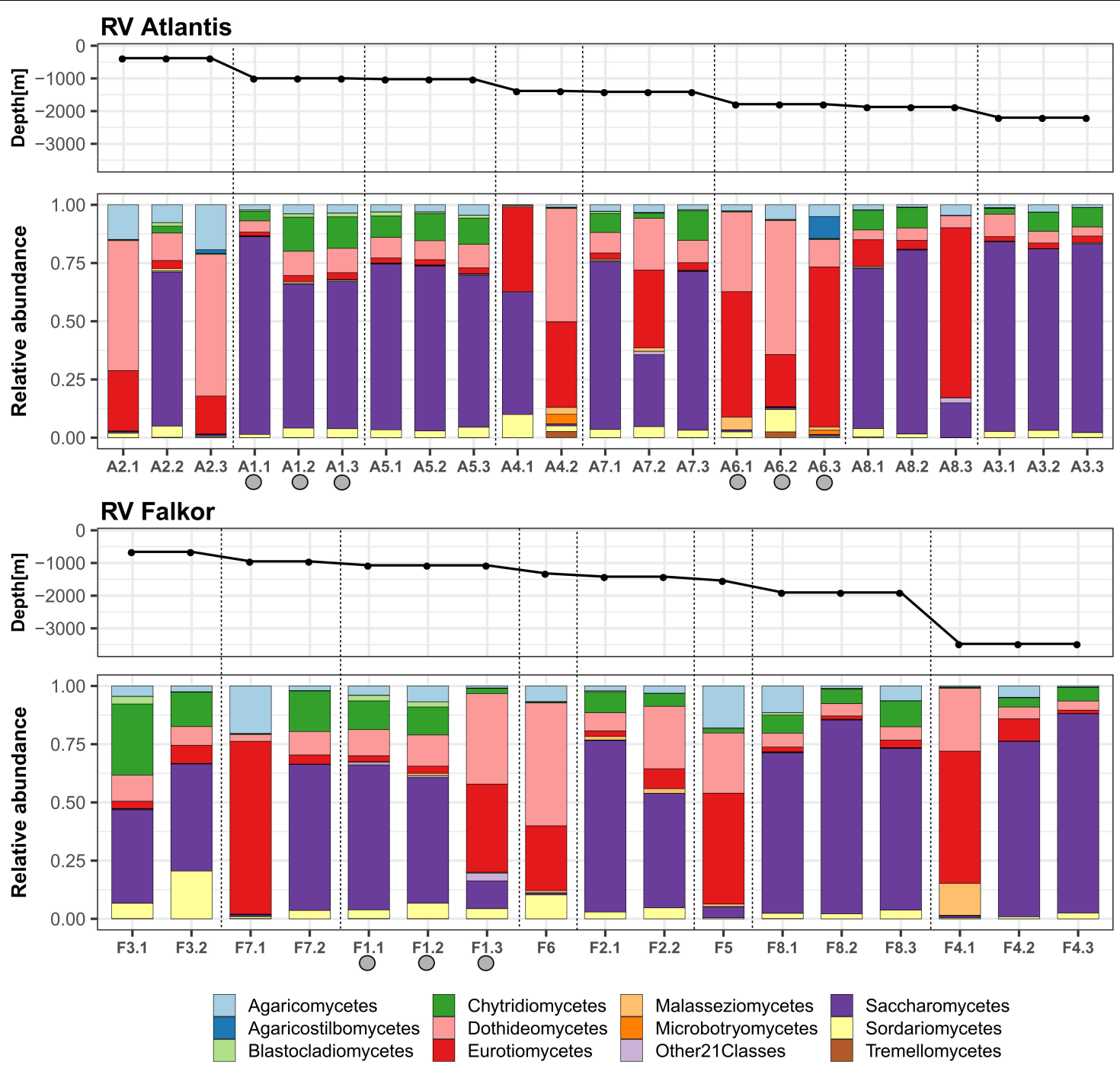

FIGURE 3 | The relative abundance of fungi, at the taxonomic level of class, in deep-sea sediments of the eastern tropical Pacific of Costa Rica. The proportions within sampling points of the core subsamples for each of the cruise transects are shown. The samples were ordered according to the depth gradient. Gray circles indicate active methane seeps.

where Saccharomycetes were practically absent (Figure 3). This observation was consistent with positive correlations within each group. For example, the correlation calculated with the Spearman method between Saccharomycetes and Chytridiomycetes was 0.80 , which implies that they were present in almost all the same samples and that they presented high values of their relative abundances. On the other hand, it was also determined that the correlations between the group dominated by Saccharomyces and the other dominated by filamentous fungi were negative (Supplementary Figure 1).

These results are consistent with those obtained, at the phylum level, in deep-sea sediments from places such as the Western and Central Pacific, the Mediterranean Sea or the São Paulo Plateau, which show Ascomycota as the most abundant group, together with the presence of Basidiomycota and Chytridiomycota in lower proportions (Li et al., 2016, 2019; Xu et al., 2016, 2019;
Zhang et al., 2016; Nagano et al., 2017; Barone et al., 2018; Wang et al., 2019). However, this is the first work that shows, to our knowledge, the fungal class Saccharomycetes as the most abundant, and also highly correlated with Chytridiomycetes, in deep-sea sediments.

We also observed high variability in the fungal composition within the horizons of some samples. In this sense, the homogeneity or heterogeneity of the horizons could be related to the specific conditions of the sampled site, which include the geochemical characteristics of the region, the sedimentation time, as well as the microbiological activity. A limitation of this study is the lack of geochemical data on sediment cores, since the data on the environmental variables of the overlying water column are not sufficient to explain what is happening in the vertical gradient of sediments. Some studies have shown large variations in physicochemical conditions in 
the profile of deep-sea sediments (Roy et al., 2012; D'Hondt et al., 2015; Román et al., 2019). Therefore, it will be necessary to continue exploring in more detail the variations in fungal communities that occur along the vertical gradient of sediment profiles.

The samples of the deep-sea environment studied, characterized by high hydrostatic pressure, low temperatures, and the absence of light, presented an average richness of 75 fungal ASVs per sample (range 13-147), while the average value of the Shannon index was 1.77 (range 0.84-2.68). As with the community analyses, there were no significant differences in the alpha diversity estimations between depths and expeditions (Kruskal-Wallis, $p>0.05$ ). The average value of the Pielou's evenness was 0.42 (range 0.21-0.71), indicating a certain uniformity in the abundances of most of the observed ASVs (Supplementary Figure 2).

The genus Metschnikowia was the most abundant within the class Saccharomycetes and also the most abundant in the majority of the sediments analyzed. The genus Metschnikowia comprises single-celled budding yeasts known for its participation in fermentation processes and wine production, reported mainly in terrestrial environments (Kang et al., 2017; Wang et al., 2017; Pawlikowska et al., 2019). There are few references to the presence of this genus in deep waters, although its presence had been previously reported in subtropical Chinese seas, including the southern and northern Yellow Sea and the Bohai Sea ( $\mathrm{Li}$ et al., 2016), but with lower abundances than those reported in this study. Also, we showed that this fungal genus was present in a wide depth gradient, from 380 to $3,474 \mathrm{~m}$, indicating that it can be highly tolerant to gradients in temperature, DO, food supply, and the hydrostatic pressure associated with this change in depth. However, in six of the studied sediment cores Metschnikowia was almost absent, pointing more to microhabitat variability.

The most abundant genus within Chytridiomycetes was Rhizophidium which can function as parasite and decomposer (Letcher et al., 2006; Kagami et al., 2007; Frenken et al., 2017), while the most abundant genera of Eurotiomycetes and Dothideomycetes were Aspergillus and Cladosporium, respectively. Previous studies have shown that Aspergillus and Penicillium are common inhabitants of deep-sea sediments; likewise, the presence of yeasts in this ecosystem has been frequently detected, but mainly related to genera such as Pichia, Cryptococcus, Malassezia, and Rhodotorula (Takishita et al., 2006; Zhang et al., 2015; Nagano et al., 2016, 2017; Grossart et al., 2019). Within Agaricomycetes, the most abundant ASV had a percentage of identity of $98.73 \%$ with Armillaria, a saprophytic genus of wood that was particularly abundant in Coco Canyon (F7) at a depth of $950 \mathrm{~m}$, which is also the site furthest from the coast. With the available information it is difficult to determine if this fungus, which is known to occur in terrestrial ecosystems, is active in these sediments.

Statistical analyzes, at the ASV level, did not show significant differences (PERMANOVA, $p>0.05$ ) in the structure of fungal communities by depth, expeditions or between filtration/non-filtration areas. Neither according to variables of the overlying water columns of sediments such as $\mathrm{pH}$, salinity and DO (Supplementary Table $\mathbf{1}$ and Supplementary Figure 3). For example, we showed that depth (and, consequently, hydrostatic pressure) does not have an apparent effect on the composition of communities, given the wide distribution range of species. In addition, the temperature, salinity, $\mathrm{DO}$ and $\mathrm{pH}$ values of the water column overlying the habitats of the two fungal clusters identified were similar (Table 2). Therefore, it seems that the conditions of the deep waters are not limiting for the growth of the fungi and that other factors, likely more related to the geochemistry of the sediments, can be influencing the composition of the communities.

As an empirical observation note, samples that contained a higher proportion of mud were the ones that exhibited

TABLE 2 | Depth, temperature, salinity, dissolved oxygen, and $\mathrm{pH}$ values of the water column overlying the habitats of the fungal clusters identified.

\begin{tabular}{lcc}
\hline Variable & $\begin{array}{c}\text { Cluster } \mathbf{1} \\
\text { (yeast } \\
\text { dominated) }\end{array}$ & $\begin{array}{c}\text { Cluster 2 } \\
\text { (filamentous } \\
\text { forms) }\end{array}$ \\
\hline Depth $(\mathrm{m})$ & $380-1,788$ & $659-3,474$ \\
Temperature $\left({ }^{\circ} \mathrm{C}\right)$ & $1.88-14.41$ & $2.54-11.75$ \\
Salinity (PSU) & $34.57-34.93$ & $34.59-34.76$ \\
Dissolved oxygen $(\mathrm{mg} / \mathrm{L})$ & $1.10-4.20$ & $0.2-2.64$ \\
$\mathrm{pH}$ & $7.60-8.06$ & $7.61-7.70$
\end{tabular}

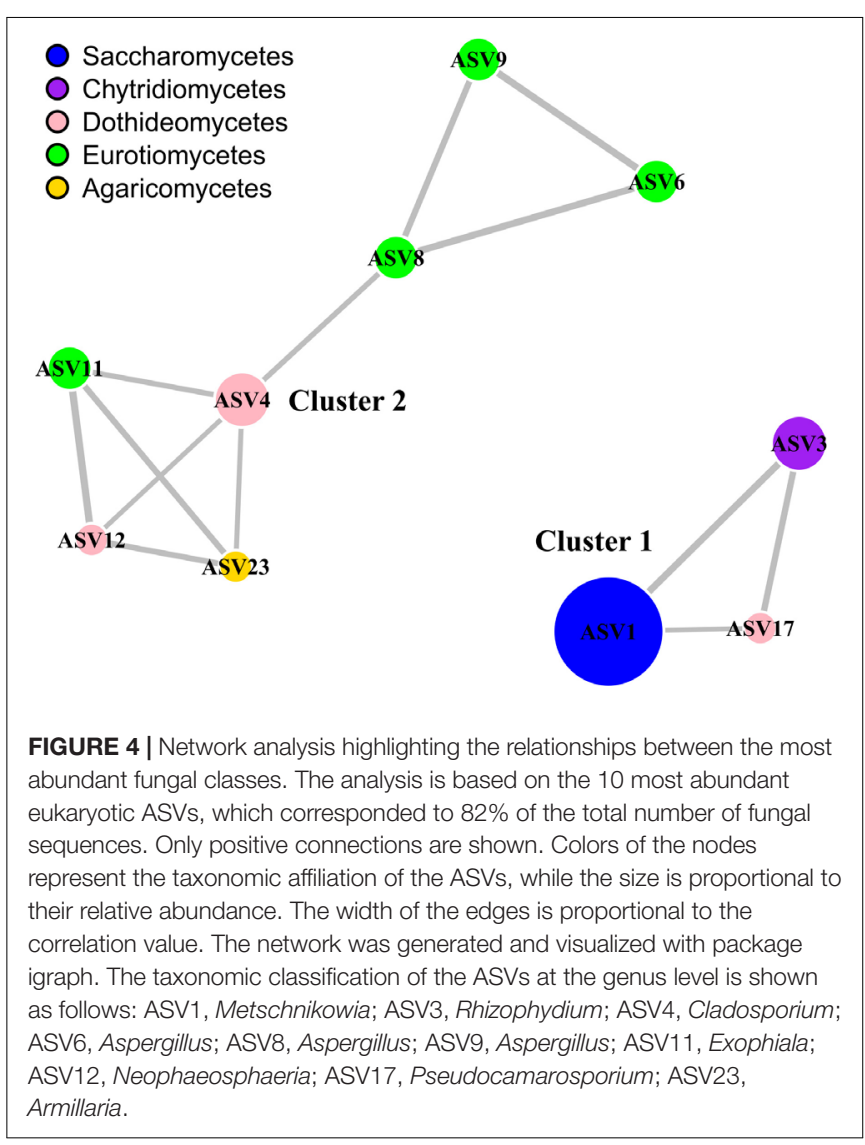


a higher abundance of Saccharomycetes. In contrast, sandy samples showed higher abundances of Eurotiomycetes and Dothideomycetes, which are filamentous fungi. This observation suggests a possible relationship between fungal morphology and its ability to colonize substrates of different textures. For example, yeasts may directly depend on the type and concentrations of organic matter found in the habitat, but could also perform fermentation processes in muddy sediments (Takishita et al., 2006; Kutty and Philip, 2008; Zhang et al., 2015; Taube et al., 2018).

We used network analysis to further explore possible relationships between the fungal groups that coexist in deep marine sediments of Costa Rica (Figure 4). This technique allowed us to visualize positive associations between the most abundant ASVs (representing $82 \%$ of the total sequences). We report a single co-occurrence and positive correlation between Metschnikowia and Rhizophydium. The association between these two taxa occurred regardless of the depth, location or conditions of the overlying water column. We have not found previous reports of the strong association between these two genera. We also report another group of co-occurring taxa that includes Cladosporium (Dothideomycetes), Aspergillus and Exophiala (Eurotiomycetes), and Armillaria (Agaricomycetes). The co-occurrence and high abundance of Cladosporium and Aspergillus is relatively common in deep-sea sediments ( $\mathrm{Li}$ et al., 2019; Wang et al., 2019; Xu et al., 2019). However, with the available information it is difficult to determine whether the positive co-occurrence can be coincidental or can indicate a true positive interaction. Based on the results of the network analysis, as a hypothesis generating tool, we hypothesized that the fungi in both clusters can be carrying out mainly heterotrophic activities, but probably in sediments with different physicochemical conditions. The nature of the interactions within clusters should be further explored. Finally, we highlight the high prevalence of fungi in deep-sea sediments of the ETP of Costa Rica. To our knowledge, this is the first work showing a high abundance of Metschnikowia in deep-sea ecosystems. The high abundance of this type of yeasts should be further studied using cultivation-dependent methods to provide better insights into the physiology, genomic makeup, and their contributions to global biogeochemical processes. Since it was difficult to distinguish the association of specific environmental variables with variations in the composition of fungal communities, particularly in the two clusters identified, further research will be necessary to determine how fungal communities in deep-sea waters are structured as well as to determine their ecological role in the largest biome on the planet.

\section{DATA AVAILABILITY STATEMENT}

The datasets presented in this study can be found in online repositories. The sequence data were deposited into the NCBI Sequence Read Archive under BioProject PRJNA632873 and BioSample accessions: SAMN14924417-SAMN14924456 (https: //www.ncbi.nlm.nih.gov/bioproject/PRJNA632873).

\section{AUTHOR CONTRIBUTIONS}

KR-J, H-PG, EC, and JC designed the study and performed the analysis. JC and EC collected the samples. KR-J wrote the manuscript. All authors helped to revise the manuscript.

\section{FUNDING}

This project was funded by Universidad de Costa Rica, DFG project GR1540/33-1 given to H-PG, and NSF OCE 1635219 awarded to EC.

\section{ACKNOWLEDGMENTS}

We would like to thank all of the officers and crew of the RV Atlantis and RV Falkor for their assistance, and the pilots of the HOV Alvin and ROV SuBastian for their efforts in the collection of samples. We thank the Ministry of Environment and Energy of Costa Rica, Instituto Costarricense de Pesca y Acuicultura (permit INCOPESCA-CPI-003-12-2018) and Comisión Nacional para la Gestión de la Biodiversidad (permit R-070-2018OT-CONAGEBIO). Sample processing was carried out with assistance from Odalisca Breedy and environmental data were compiled by Steve Auscavitch, Jay Lunden, and April Stabbins at Temple University. We also thank Lisa Levin and Greg Rouse at Scripps Oceanography, UC San Diego, La Jolla, CA, and Victoria Orphan at the California Institute of Technology, Pasadena, CA for their support during the development of this project. We acknowledge the support of the Deutsche Forschungsgemeinschaft and Open Access Publishing Fund of University of Potsdam. We thank the reviewers for their critical comments on the manuscript.

\section{SUPPLEMENTARY MATERIAL}

The Supplementary Material for this article can be found online at: https://www.frontiersin.org/articles/10.3389/fmicb.2020. 575207/full\#supplementary-material

Supplementary Figure 1 | Correlogram highlighting the most correlated classes of fungi in points in deep-sea sediments of the Eastern Tropical Pacific, based on Spearman correlation.

Supplementary Figure 2 | Boxplots of the alpha diversity estimations of the sampling points in deep-sea sediments of the Eastern Tropical Pacific.

Supplementary Figure 3 | Non-metric multidimensional scaling (NMDS) analyses of the fungal communities in deep-sea sediments. The analysis include 40 samples from sediments obtained in a bathymetric gradient (from a depth of 380 to $3,474 \mathrm{~m}$ ) along two transects of about $1,500 \mathrm{~km}$ length in the Eastern Tropical Pacific of Costa Rica. The upper panel shows the analysis by transect and the lower the analysis by depth. The stress values of the NMDS and the $p$ value of the PERMANOVA analyses are also shown.

Supplementary Table 1 | Statistical analysis of the fungal community composition related to different variables. The PERMANOVA tests were performed using function adonis2 and implemented in Vegan package. Data were normalized by converting the ASV counts into relative abundances. Binning of continuous variables Depth, Temperature, Dissolved Oxygen and $\mathrm{pH}$ was performed with package Hmisc. 


\section{REFERENCES}

Barone, G., Rastelli, E., Corinaldesi, C., Tangherlini, M., Danovaro, R., and Dell'Anno, A. (2018). Benthic deep-sea fungi in submarine canyons of the Mediterranean Sea. Prog. Oceanogr. 168, 57-64. doi: 10.1016/j.pocean.2018. 09.011

Batista-García, R. A., Sutton, T., Jackson, S. A., Tovar-Herrera, O. E., BalcázarLópez, E., del Rayo Sánchez-Carbente, M., et al. (2017). Characterization of lignocellulolytic activities from fungi isolated from the deep-sea sponge stelletta normani. PLoS One 12:e0173750. doi: 10.1371/journal.pone.0173750

Bochdansky, A. B., Clouse, M. A., and Herndl, G. J. (2017). Eukaryotic microbes, principally fungi and labyrinthulomycetes, dominate biomass on bathypelagic marine snow. ISME J. 11, 362-373. doi: 10.1038/ismej.2016.113

Callahan, B. J., McMurdie, P. J., Rosen, M. J., Han, A. W., Johnson, A. J. A., and Holmes, S. P. (2016). DADA2: high-resolution sample inference from Illumina amplicon data. Nat. Methods 13,581-583. doi: 10.1038/nmeth.3869

Cortés, J. (2008). Historia de la investigación marina de la Isla del Coco, Costa Rica. Rev. Biol. Trop. 56, 1-18.

Cortés, J. (2012). Marine biodiversity of an eastern tropical pacific oceanic island, Isla del coco, costa rica. Rev. Biol. Trop. 60, 131-185.

Cortés, J. (2016). "The pacific coastal and marine ecosystems," in Costa Rican Ecosystems, ed. M. Kappelle (Chicago: The University of Chicago Press), 97138. doi: $10.7208 /$ chicago/9780226121642.003.0005

Cortés, J. (2019). "Isla del coco, costa rica, eastern tropical pacific, " in Mesophotic Coral Ecosystems, Vol 12, eds Y. Loya, K. Puglise, T. Bridge (Berlin: Springer), 465-475. doi: 10.1007/978-3-319-927 35-0_26

Csardi, G., and Nepusz, T. (2006). The igraph software package for complex network research. InterJournal Complex Syst. 1695, 1-9.

Dekas, A. E., Connon, S. A., Chadwick, G. L., Trembath-Reichert, E., and Orphan, V. J. (2016). Activity and interactions of methane seep microorganisms assessed by parallel transcription and FISH-NanoSIMS analyses. ISME J. 10, 678-692. doi: 10.1038/ismej.2015.145

D'Hondt, S. (2002). Metabolic activity of subsurface life in deep-sea sediments. Science 295, 2067-2070. doi: 10.1126/science.1064878

D’Hondt, S., Inagaki, F., Zarikian, C. A., Abrams, L. J., Dubois, N., Engelhardt, T., et al. (2015). Presence of oxygen and aerobic communities from sea floor to basement in deep-sea sediments. Nat. Geosci. 8, 299-304. doi: 10.1038/ ngeo 2387

Dickson, A. G., Sabine, C. L., and Christian, J. R. (2007). Guide to Best Practices for Ocean CO2 Measurements. PICES Special Publication 3, 191. Available online at: https://www.nodc.noaa.gov/ocads/oceans/Handbook_2007.html

Drake, H., and Ivarsson, M. (2018). The role of anaerobic fungi in fundamental biogeochemical cycles in the deep biosphere. Fungal Biol. Rev. 32, 20-25. doi: 10.1016/j.fbr.2017.10.001

Edgcomb, V. P., Beaudoin, D., Gast, R., Biddle, J. F., and Teske, A. (2011). Marine subsurface eukaryotes: the fungal majority. Environ. Microbiol. 13, 172-183. doi: 10.1111/j.1462-2920.2010.02318.x

Frenken, T., Alacid, E., Berger, S. A., Bourne, E. C., Gerphagnon, M., Grossart, H. P., et al. (2017). Integrating chytrid fungal parasites into plankton ecology: research gaps and needs. Environ. Microbiol. 19, 3802-3822. doi: 10.1111/14622920.13827

Grossart, H.-P., Van den Wyngaert, S., Kagami, M., Wurzbacher, C., Cunliffe, M., and Rojas-Jimenez, K. (2019). Fungi in aquatic ecosystems. Nat. Rev. Microbiol. 17, 339-354. doi: 10.1038/s41579-019-0175-8

Grossart, H.-P. H.-P. P., and Rojas-Jimenez, K. (2016). Aquatic fungi: targeting the forgotten in microbial ecology. Curr. Opin. Microbiol. 31, 140-145. doi: 10.1016/j.mib.2016.03.016

Hassett, B. T., Vonnahme, T. R., Peng, X., Jones, E. B. G., and Heuzé, C. (2020). Global diversity and geography of planktonic marine fungi. Bot. Mar. 63, 121-139. doi: 10.1515/bot-2018-0113

Ivarsson, M., Bengtson, S., and Neubeck, A. (2016a). The igneous oceanic crust Earth's largest fungal habitat? Fungal Ecol. 20, 249-255. doi: 10.1016/j.funeco. 2016.01.009

Ivarsson, M., Schnürer, A., Bengtson, S., and Neubeck, A. (2016b). Anaerobic fungi: a potential source of biological H2 in the oceanic crust. Front. Microbiol. 7:674. doi: $10.3389 /$ fmicb. 2016.00674
Junker, B. H. (2007). "Networks in Biology," in Analysis of Biological Networks, eds Y. Pan, A. Y. Zomaya, B. H. Junker and F. Schreiber. doi: 10.1002/ 9780470253489.ch1

Kagami, M., de Bruin, A., Ibelings, B. W., and Van Donk, E. (2007). Parasitic chytrids: their effects on phytoplankton communities and food-web dynamics. Hydrobiologia 578, 113-129. doi: 10.1007/s10750-006-0438-Z

Kang, Y. M., Choi, J. E., Komakech, R., Park, J. H., Kim, D. W., Cho, K. M., et al. (2017). Characterization of a novel yeast species metschnikowia persimmonesis KCTC 12991BP (KIOM G15050 type strain) isolated from a medicinal plant, Korean persimmon calyx (diospyros kaki thumb). AMB Express 7:199. doi: 10.1186/s13568-017-0503-1

Kutty, S. N., and Philip, R. (2008). Marine yeasts-a review. Yeast 25, 465-483. doi: 10.1002/yea.1599

Le Calvez, T., Burgaud, G., Mahé, S., Barbier, G., Vandenkoornhuyse, P., Mahe, S., et al. (2009). Fungal diversity in deep-sea hydrothermal ecosystems. Appl. Environ. Microbiol. 75, 6415-6421. doi: 10.1128/AEM.00653-09

Lenhart, K., Bunge, M., Ratering, S., Neu, T. R., Schüttmann, I., Greule, M., et al. (2012). Evidence for methane production by saprotrophic fungi. Nat. Commun. 3:1046. doi: 10.1038/ncomms2049

Letcher, P. M., Powell, M. J., Churchill, P. F., and Chambers, J. G. (2006). Ultrastructural and molecular phylogenetic delineation of a new order, the Rhizophydiales (Chytridiomycota). Mycol. Res. 110, 898-915. doi: 10.1016/j. mycres.2006.06.011

Levin, L. A., Mendoza, G. F., Grupe, B. M., Gonzalez, J. P., Jellison, B., Rouse, G., et al. (2015). Correction: biodiversity on the rocks: macrofauna inhabiting authigenic carbonate at costa rica methane seeps. PLoS One 10:e0136129. doi: 10.1371/journal.pone.0136129

Levin, L. A., Orphan, V. J., Rouse, G. W., Rathburn, A. E., Ussler, W., Cook, G. S., et al. (2012). A hydrothermal seep on the Costa Rica margin: middle ground in a continuum of reducing ecosystems. Proc. R. Soc. B Biol. Sci. 279, 2580-2588. doi: 10.1098/rspb.2012.0205

Li, W., Wang, M., Burgaud, G., Yu, H., and Cai, L. (2019). Fungal community composition and potential depth-related driving factors impacting distribution pattern and trophic modes from epi- to abyssopelagic zones of the Western Pacific Ocean. Microb. Ecol. 78, 820-831. doi: 10.1007/s00248-019-01374-y

Li, W., Wang, M. M., Wang, X. G., Cheng, X. L., Guo, J. J., Bian, X. M., et al. (2016). Fungal communities in sediments of subtropical Chinese seas as estimated by DNA metabarcoding. Sci. Rep. 6, 26528. doi: 10.1038/srep26528

Lizano, O. (2001). Batimetria de la plataforma insular alrededor de las Isla del coco, costa rica. Rev. Biol. Trop. 49(Suppl.), 163-170.

López-García, P., Philippe, H., Gail, F., and Moreira, D. (2003). Autochthonous eukaryotic diversity in hydrothermal sediment and experimental microcolonizers at the mid-atlantic ridge. Proc. Natl. Acad. Sci. U.S.A. 100, 697-702. doi: 10.1073/pnas.0235779100

Manohar, C. S., and Raghukumar, C. (2013). Fungal diversity from various marine habitats deduced through culture-independent studies. FEMS Microbiol. Lett. 341, 69-78. doi: 10.1111/1574-6968.12087

Morales, S. E., Biswas, A., Herndl, G. J., and Baltar, F. (2019). Global Structuring of phylogenetic and functional diversity of pelagic fungi by depth and temperature. Front. Mar. Sci. 6:131. doi: 10.3389/fmars.2019.00131

Nagahama, T., Takahashi, E., Nagano, Y., Abdel-Wahab, M. A., and Miyazaki, M. (2011). Molecular evidence that deep-branching fungi are major fungal components in deep-sea methane cold-seep sediments. Environ. Microbiol. 13, 2359-2370. doi: 10.1111/j.1462-2920.2011.02507.x

Nagano, Y., Konishi, M., Nagahama, T., Kubota, T., Abe, F., and Hatada, Y. (2016). Retrieval of deeply buried culturable fungi in marine subsurface sediments, Suruga-Bay, Japan. Fungal. Ecol. 20, 256-259. doi: 10.1016/j.funeco.2015. 12.012

Nagano, Y., Miura, T., Nishi, S., Lima, A. O., Nakayama, C., Pellizari, V. H., et al. (2017). Fungal diversity in deep-sea sediments associated with asphalt seeps at the São Paulo Plateau. Deep Sea Res. Part II Top. Stud. Oceanogr. 146, 59-67. doi: 10.1016/j.dsr2.2017.05.012

Nagano, Y., and Nagahama, T. (2012). Fungal diversity in deep-sea extreme environments. Fungal Ecol. 5, 463-471. doi: 10.1016/j.funeco.2012.01.004

Nealson, K. H., Inagaki, F., and Takai, K. (2005). Hydrogen-driven subsurface lithoautotrophic microbial ecosystems (SLiMEs): do they exist and why should we care? Trends Microbiol. 13, 405-410. doi: 10.1016/j.tim.2005.07.010 
Oksanen, J., Blanchet, F. G., Friendly, M., Kindt, R., Legendre, P., McGlinn, D., et al. (2020). vegan: Community Ecology Package (R package version 2.5-6).

Pachiadaki, M. G., Rédou, V., Beaudoin, D. J., Burgaud, G., and Edgcomb, V. P. (2016). Fungal and prokaryotic activities in the marine subsurface biosphere at Peru margin and Canterbury Basin inferred from RNA-based analyses and microscopy. Front. Microbiol. 7:846. doi: 10.3389/fmicb.2016.00846

Pawlikowska, E., James, S. A., Breierova, E., Antolak, H., and Kregiel, D. (2019). Biocontrol capability of local Metschnikowia sp. isolates. Antonie Van Leeuwenhoek 112, 1425-1445. doi: 10.1007/s10482-019-01272-w

Protti, M., González, V., Freymueller, J., and Doelger, S. (2012). Isla del Coco, on Cocos Plate, converges with Isla de San Andrés, on the Caribbean Plate, at $78 \mathrm{~mm} /$ yr. Rev. Biol. Trop. 60, 33-41.

Quast, C., Pruesse, E., Yilmaz, P., Gerken, J., Schweer, T., Yarza, P., et al. (2013). The SILVA ribosomal RNA gene database project: improved data processing and web-based tools. Nucleic Acids Res. 41, D590-D596. doi: 10.1093/nar/gks1219

R-Core-Team (2019). R: A Language and Environment for Statistical Computing.

Rojas, W., and Alvarado, G. E. (2012). Marco geológico y tectónico de la Isla del Coco y la región marítima circunvecina, Costa Rica zone off the central Pacific coast of Costa Rica. Rev. Biol. Trop. 60, 15-32.

Rojas-Jiménez, K. (2018). Microorganismos del corredor marino isla del cocogalápagos: diversidad funcional y de especies. Rev. Tecnol. en Marcha 31, 157-166. doi: 10.18845/tm.v31i4.3974

Román, S., Ortiz-Álvarez, R., Romano, C., Casamayor, E. O., and Martin, D. (2019). Microbial community structure and functionality in the deep sea floor: evaluating the causes of spatial heterogeneity in a submarine canyon system (NW Mediterranean, Spain). Front. Mar. Sci. 6:108. doi: 10.3389/fmars.2019. 00108

Roy, H., Kallmeyer, J., Adhikari, R. R., Pockalny, R., Jorgensen, B. B., and D’Hondt, S. (2012). Aerobic microbial respiration in 86-million-year-old deep-sea red clay. Science 336, 922-925. doi: 10.1126/science.1219424

Rusch, D. B., Halpern, A. L., Sutton, G., Heidelberg, K. B., Williamson, S., Yooseph, S., et al. (2007). The sorcerer II global ocean sampling expedition: northwest atlantic through Eastern Tropical Pacific. PLoS Biol. 5:e77. doi: 10.1371/journal. pbio. 0050077

Sahling, H., Masson, D. G., Ranero, C. R., Hühnerbach, V., Weinrebe, W., Klaucke, I., et al. (2008). Fluid seepage at the continental margin offshore Costa Rica and southern Nicaragua. Geochem. Geophys. Geosyst. 9, 1-22. doi: 10.1029/ 2008GC001978

Takishita, K., Tsuchiya, M., Reimer, J. D., and Maruyama, T. (2006). Molecular evidence demonstrating the basidiomycetous fungus Cryptococcus curvatus is the dominant microbial eukaryote in sediment at the Kuroshima Knoll methane seep. Extremophiles 10, 165-169. doi: 10.1007/s00792-0050495-7

Taube, R., Ganzert, L., Grossart, H.-P., Gleixner, G., and Premke, K. (2018). Organic matter quality structures benthic fatty acid patterns and the abundance of fungi and bacteria in temperate lakes. Sci. Total Environ. 61, 469-481. doi: 10.1016/j.scitotenv.2017.07.256
Vainio, E. J., and Hantula, J. (2000). Direct analysis of wood-inhabiting fungi using denaturing gradient gel electrophoresis of amplified ribosomal DNA. Mycol. Res. 104, 927-936. doi: 10.1017/S0953756200002471

Wang, C., Liu, Y., Zhang, T., Lu, C., Liu, Y., Zhang, D., et al. (2017). Metschnikowia persici sp. nov., a novel protease-producing yeast species from China. Curr. Microbiol. 74, 365-370. doi: 10.1007/s00284-017-1194-1

Wang, Z.-P., Liu, Z.-Z., Wang, Y.-L., Bi, W.-H., Liu, L., Wang, H.-Y., et al. (2019). Fungal community analysis in seawater of the mariana trench as estimated by Illumina HiSeq. RSC Adv. 9, 6956-6964. doi: 10.1039/C8RA10142F

Xu, W., Gao, Y., Gong, L., Li, M., Pang, K.-L., and Luo, Z.-H. (2019). Fungal diversity in the deep-sea hadal sediments of the yap trench by cultivation and high throughput sequencing methods based on ITS rRNA gene. Deep Sea Res. Part I Oceanogr. Res. Pap. 145, 125-136. doi: 10.1016/j.dsr.2019.02.001

Xu, W., Guo, S., Pang, K.-L., and Luo, Z.-H. (2017). Fungi associated with chimney and sulfide samples from a South Mid-Atlantic Ridge hydrothermal site: distribution, diversity and abundance. Deep Sea Res. Part I Oceanogr. Res. Pap. 123, 48-55. doi: 10.1016/j.dsr.2017.03.004

Xu, W., Luo, Z.-H., Guo, S., and Pang, K.-L. (2016). Fungal community analysis in the deep-sea sediments of the Pacific Ocean assessed by comparison of ITS, $18 \mathrm{~S}$ and 28S ribosomal DNA regions. Deep Sea Res. Part I Oceanogr. Res. Pap. 109, 51-60. doi: 10.1016/j.dsr.2016.01.001

Xu, Z., Wang, M., Wu, W., Li, Y., Liu, Q., Han, Y., et al. (2018). Vertical distribution of microbial eukaryotes from surface to the hadal zone of the mariana trench. Front. Microbiol. 9:2023. doi: 10.3389/fmicb.2018.02023

Zhang, T., Fei Wang, N., Qin Zhang, Y., Yu Liu, H., and Yan Yu, L. (2015). Diversity and distribution of fungal communities in the marine sediments of Kongsfjorden, Svalbard (High Arctic). Sci. Rep. 5:14524. doi: 10.1038/ srep 14524

Zhang, X., Tang, G., Xu, X., Nong, X., and Qi, S.-H. (2014). Insights into deepsea sediment fungal communities from the east indian ocean using targeted environmental sequencing combined with traditional cultivation. PLoS One 9:e109118. doi: 10.1371/journal.pone.0109118

Zhang, X.-Y., Wang, G.-H., Xu, X.-Y., Nong, X.-H., Wang, J., Amin, M., et al. (2016). Exploring fungal diversity in deep-sea sediments from Okinawa Trough using high-throughput Illumina sequencing. Deep Sea Res. Part I Oceanogr. Res. Pap. 116, 99-105. doi: 10.1016/j.dsr.2016.08.004

Conflict of Interest: The authors declare that the research was conducted in the absence of any commercial or financial relationships that could be construed as a potential conflict of interest.

Copyright (c) 2020 Rojas-Jimenez, Grossart, Cordes and Cortés. This is an open-access article distributed under the terms of the Creative Commons Attribution License (CC BY). The use, distribution or reproduction in other forums is permitted, provided the original author(s) and the copyright owner(s) are credited and that the original publication in this journal is cited, in accordance with accepted academic practice. No use, distribution or reproduction is permitted which does not comply with these terms. 